\title{
The engaged patient: patient activation can predict satisfaction with surgical treatment of lumbar and cervical spine disorders
}

\author{
Andrew B. Harris, BS, ${ }^{1}$ Floreana Kebaish, MD, ${ }^{1}$ Lee H. Riley III, MD,, Khaled M. Kebaish, MD, ${ }^{1}$ and \\ Richard L. Skolasky, ScD1,2
}

Departments of ${ }^{1}$ Orthopaedic Surgery and ${ }^{2}$ Physical Medicine and Rehabilitation, The Johns Hopkins University, Baltimore, Maryland

\begin{abstract}
OBJECTIVE Care satisfaction is an important metric to health systems and payers. Patient activation is a hierarchical construct following 4 stages: 1) having a belief that taking an active role in their care is important, 2) having knowledge and skills to manage their condition, 3) having the confidence to make necessary behavioral changes, and 4) having an ability to maintain those changes in times of stress. The authors hypothesized that patients with a high level of activation, measured using the Patient Activation Measure (PAM), will be more engaged in their care and, therefore, will be more likely to be satisfied with the results of their surgical treatment.
\end{abstract}

METHODS Using a prospectively collected registry at a multiprovider university practice, the authors examined patients who underwent elective surgery $(n=257)$ for cervical or lumbar spinal disorders. Patients were assessed before and after surgery (6 weeks and 3, 6, and 12 months) using Patient-Reported Outcomes Measurement Information System (PROMIS) health domains and the PAM. Satisfaction was assessed using the Patient Satisfaction Index. Using repeated-measures logistic regression, the authors compared the likelihood of being satisfied across stages of patient activation after adjusting for baseline characteristics (i.e., age, sex, race, education, income, and marital status).

RESULTS While a majority of patients endorsed the highest level of activation (56\%), $51(20 \%)$ endorsed the lower two stages (neither believing that taking an active role was important nor having the knowledge and skills to manage their condition). Preoperative patient activation was weakly correlated $(r \leq 0.2)$ with PROMIS health domains. The most activated patients were 3 times more likely to be satisfied with their treatment at 1 year (OR $3.23,95 \% \mathrm{Cl} 1.8-5.8)$. Similarly, patients in the second-highest stage of activation also demonstrated significantly greater odds of being satisfied (OR 2.8, 95\% Cl 1.5-5.3).

CONCLUSIONS Patients who are more engaged in their healthcare prior to elective spine surgery are significantly more likely to be satisfied with their postoperative outcome. Clinicians may want to implement previously proven techniques to increase patient activation in order to improve patient satisfaction following elective spine surgery.

https://thejns.org/doi/abs/10.3171/2019.11.SPINE191159

KEYWORDS satisfaction; cervical; lumbar; PROMIS; PROs; patient-reported outcomes; Patient Activation Measure; PAM; quality improvement

$\mathrm{P}$ ATIENT satisfaction is an important and measurable component of surgical care. ${ }^{1,9,32}$ Aside from the obvious importance of patient satisfaction to both patients and providers, health systems and payers have also become increasingly focused on measuring and maximizing patient satisfaction. Satisfaction scores have been a key marker in hospital quality improvement initiatives ${ }^{1,14}$ and are now used to adjust reimbursements from private in- surers. ${ }^{15}$ As we move toward a healthcare system that emphasizes patient-centeredness, patient accountability, and patient engagement, identifying the patient-related factors that lead to increased satisfaction becomes increasingly important.

Many of the factors that affect the satisfaction of patients undergoing surgery are intuitive, such as the surgeon's attentiveness on the day of surgery, effective preopera-

ABBREVIATIONS PAM = Patient Activation Measure; PROMIS = Patient-Reported Outcomes Measurement Information System. SUBMITTED October 3, 2019. ACCEPTED November 27, 2019.

INCLUDE WHEN CITING Published online February 7, 2020; DOI: 10.3171/2019.11.SPINE191159. 
tive communication, decreased waiting room times, and shorter hospital stays; ${ }^{3,16,21}$ however, some of the research on factors that drive satisfaction in surgical patients has shown less intuitive results. For example, studies indicate that patient satisfaction may be independent of issues such as postsurgical pain ${ }^{9}$ and adherence to evidence-based guidelines by surgeons. ${ }^{15}$ Therefore, surgeons seeking to improve the satisfaction of their patients must be aware of this complex, multifactorial metric and the factors that drive it.

"Patient activation," as defined by Hibbard et al., is a construct used to describe the degree to which patients: 1) believe that taking an active role in their care is important; 2) have the knowledge and skills to manage their condition; 3) have the confidence to make necessary behavioral changes; and 4) can persist in those changes in times of stress. ${ }^{12}$ Patient activation is a component of overall "patient engagement." Though "patient activation" and "patient engagement" are often used interchangeably in the outcomes assessment literature, they are unique terms that help us define the patient experience as we move away from labeling patients as "compliant" or "noncompliant" with the treatment plan and recommendations that are prescribed by healthcare providers. ${ }^{11}$

Several studies have shown that conscious efforts to engage patients in their own care lead to improved outcomes in various specialties. ${ }^{10,20,24,33}$ Previously, we have demonstrated that patients undergoing lumbar spine surgery vary on their level of patient activation and that higher levels of activation lead to improved postsurgical recovery and engagement in postoperative rehabilitation. ${ }^{23,24}$ In addition, patient activation is modifiable, with brief interventions that have been described to improve activation and outcomes. ${ }^{7,11,27,28}$ In addition, patient activation is in alignment with key priorities outlined in 2012 by the Patient-Centered Outcomes Research Institute. Thus, understanding the relationship between patient activation and postsurgical satisfaction is of great value to our understanding and advancement of patient-centered care.

We hypothesized that patients who display higher levels of patient activation prior to surgery are more likely to be satisfied with the results of their operative care. Therefore, the primary aim of this study was to determine whether activated patients are more likely to be satisfied with the results of their surgical treatment following elective spinal surgery. In addition, we sought to examine the relationship between patient activation and other validated outcome measures in patients undergoing spine surgery in order to better understand how this construct is related to known health-related quality of life domains in this patient population.

\section{Methods}

This study received approval from our institution's institutional review board.

\section{Study Population}

Patients presenting to a multiprovider, academic spine center between 2014 and 2017 who received elective surgical treatment of lumbar or cervical spinal disorders were eligible for inclusion in our prospectively collected spine outcomes registry. At each visit, patients are offered the opportunity to complete a series of questionnaires. These visits are typically preoperatively and at 6 weeks, 3 months, 6 months, and 1 year following surgery. Patients with complete preoperative and follow-up questionnaires at the 1-year postoperative visit were included in the final cohort for analysis (Fig. 1).

\section{Measurement of Patient Activation}

The Patient Activation Measure (PAM) is a questionnaire composed of 13 questions designed to determine how "engaged and active" patients are in their own healthcare. The questionnaire was developed initially by Hibbard and colleagues in 2004, ${ }^{12}$ and it assesses the degree to which patients believe that taking an active role is important, have the confidence and knowledge to take action, have the confidence to make necessary behavioral changes, and have the ability to stay the course under stress. The PAM score is a continuous measure from 0 (no activation) to 100 (high activation). The PAM has been previously demonstrated to be reliable and valid in patients who are undergoing lumbar spinal surgery. ${ }^{22}$

\section{Patient-Reported Outcomes Measures}

The Patient-Reported Outcomes Measurement Information System (PROMIS) was developed by an NIHfunded, multicenter cooperative group starting in $2004 .^{5}$ PROMIS has been used to measure outcomes in various healthcare fields and has recently been shown to be valid and responsive in patients undergoing both lumbar ${ }^{19}$ and cervical $^{18}$ spine surgery. Patients were assessed using the following 7 health domains: anxiety, depression, fatigue, pain, physical function, satisfaction with participation with social roles, and sleep disturbance. Patients were asked to record their responses on a scale from 1 to 5 , based on how they were feeling "in the past seven days." Scores were reported on a T-score metric, with a mean of 50 and SD of \pm 10 , centered at the mean calculated from a sample of the 2000 census, in line with similar age, sex, race, and educational level. ${ }^{4,17}$

\section{Measurement of Patient Satisfaction}

Using the North American Spine Society's Patient Satisfaction Index, patients were characterized as satisfied (i.e., treatment met expectations) versus not satisfied (all other responses). The Patient Satisfaction Index is designed to assess the degree to which a patient's treatment met their expectations and if the patient would be willing to undergo the same treatment again. ${ }^{6}$ Patients are classified in the following categories: "the treatment met my expectations"; "I did not improve as much as I had hoped, but I would undergo the same treatment for the same outcome"; and "I did not improve as much as I had hoped, and I would not undergo the same treatment for the same outcome" or "I am the same or worse than before my treatment." Patients who would undergo the same treatment were classified as satisfied, while patients who would not undergo the same treatment were classified as not satisfied. 


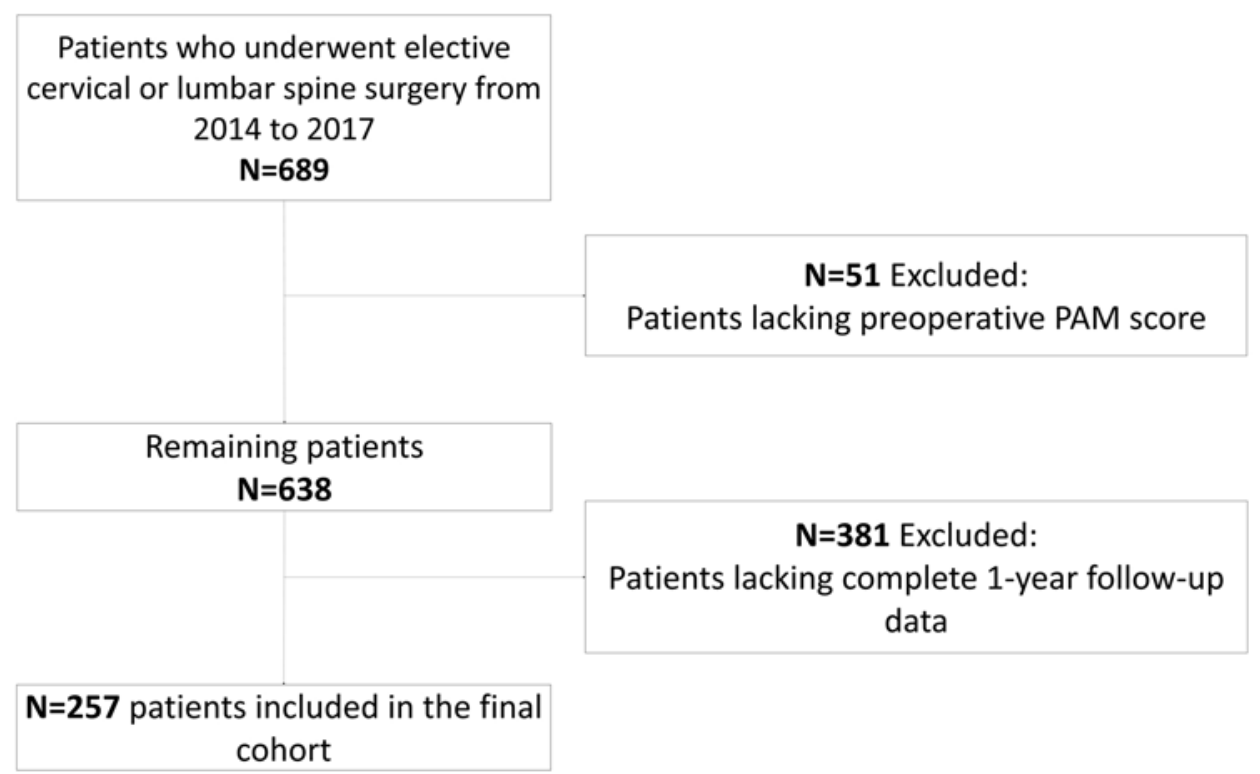

FIG. 1. Patient selection flowchart. Initially, 689 patients were identified who underwent elective cervical or lumbar spine surgery from 2014 to 2017. Fifty-one patients, who lacked preoperative PAM scores, were excluded, and an additional 381 patients, who lacked complete 1-year follow-up data, were also excluded.

\section{Analysis of Patients With Incomplete Data}

In order to assess the potential for selection bias due to excluding patients with a lack of 1-year follow-up data, we separately analyzed the association between patient activation and satisfaction in patients who met inclusion criteria and were eligible for 1-year follow-up but only had 6-month data available. The results of this sensitivity analysis were compared to those of the main analysis of patients with complete 1-year follow-up data.

\section{Statistical Analysis}

Descriptive statistics were calculated and are displayed as means \pm SD or the number (percentage), unless stated otherwise. Pearson's correlation was primarily used to identify the relationship between PROMIS health domains and PAM scores. In addition, Pearson's correlation was used to investigate the relationship between postoperative satisfaction and PROMIS health domains. Repeated-measures binary logistic regression was used to compared the likelihood of being satisfied with surgical results across stages of patient activation, after adjusting for baseline characteristics that included age, sex, race, highest level of education, and marital status. The reference category was the lowest stage of patient activation (stage 1). Significance was set at $p=0.05$. Data were analyzed using STATA release 15 (StataCorp).

\section{Results \\ Patient Sample}

The study included 257 patients, whose mean age was $60 \pm 12.2$ years, and 151 (59\%) were female. Fourteen patients $(5.5 \%)$ reported being active smokers. While a majority of patients (56\%) endorsed the highest level of activation, $21(8.2 \%)$ endorsed the lowest stage (i.e., did not believe taking an active role was important). The remainder endorsed the second and third stages of activation (12\% and 25\%, respectively). Patients had the following preoperative PROMIS health domain scores: pain $64 \pm$ 7.5; physical function $35 \pm 7.4$; fatigue $58 \pm 9.3$; anxiety 55 \pm 9.0 ; depression $51 \pm 9.5$; sleep $56 \pm 9.4$; and social status $40 \pm 8.7$. Characteristics of our study population can be seen in Table 1.

\section{Association Between PROMIS Health Domains and the PAM}

The following preoperative PROMIS health domains showed significant correlation with the preoperative PAM scores: fatigue, anxiety, depression, and satisfaction with social role (all $\mathrm{p} \leq 0.01$ ). The PROMIS pain, physical function, and sleep disturbance domains were not significantly correlated with PAM scores (all $p>0.05$ ). For PROMIS health domains that were significantly correlated, the strength of correlation was weak (all $\mathrm{r} \leq 0.2)$ (Fig. 2).

\section{Postoperative Satisfaction Stratified by Stages of Preoperative Patient Activation}

Patients who endorsed the highest stage of preoperative patient activation (stage 4) had consistently higher odds of being satisfied at all postoperative assessments (OR 3.06-5.41, p 5 0.01). Patients in the second-highest stage of patient activation (stage 3) also had significantly greater odds of being satisfied at all postoperative assessments (OR 2.82-4.75, $\mathrm{p} \leq 0.01$ ) (Table 2). Patients in the second-lowest stage (stage 2) did not have significantly greater odds of being satisfied at any postoperative assessment $(\mathrm{p}>0.05)$.

Satisfaction was also significantly correlated with the 
majority of PROMIS health domains. A positive correlation (indicating that more satisfied patients have more favorable outcomes) was seen with the PROMIS domains of fatigue, anxiety, and depression $(\mathrm{r}=0.18-0.24$, all $\mathrm{p}<$ 0.01 ). A negative correlation (indicating that more satisfied patients have less favorable outcomes) was seen with the PROMIS satisfaction with social roles domain $(\mathrm{r}=-0.21$, $\mathrm{p}<0.01)$ (Table 3).

\section{Carry-Forward Analysis Including Patients With Incomplete Data}

As a secondary analysis of patients with incomplete 1-year follow-up data, 381 patients had at least 6 months of follow-up and were analyzed using either 6- or 12-month satisfaction as the primary outcome. In this group of patients, preoperative patient activation was also significantly associated with postoperative satisfaction, with higher odds than in the study population with complete 1-year follow-up data. Patients with a preoperative activation stage of 4 had 6.6 times greater odds of being satisfied than those with a preoperative activation stage of $1(95 \%$ CI $2.5-16.9, \mathrm{p}<0.01)$. Similarly increased odds of satisfaction were seen in patients with stage 3 (OR 4.3, 95\% CI 1.5-11.0) and stage 2 (OR 5.0, 95\% CI 1.6-14.8) activation.

\section{Discussion}

Our results demonstrate that patients who are more engaged in their care prior to elective spine surgery are subsequently more likely to be satisfied at 1 year postoperatively. In addition, satisfaction is positively correlated with improved outcomes in the several PROMIS health domains. In our patient population, roughly half of patients scored in the highest level of patient activation at baseline, and patient activation was weakly correlated with PROMIS health domains. To our knowledge, this study is the first to demonstrate a relationship between patient activation and satisfaction in patients undergoing elective spine surgery.

Patient satisfaction following surgical procedures is complex and has many contributing factors. When examining patient satisfaction alongside national hospital data, Tevis et al. found that high hospital surgical volume, large hospital size, and low risk-adjusted mortality were associated with higher patient satisfaction; however, rate of surgical complications, readmissions, and patient safety indicators were not. ${ }^{29}$ Along the same lines, Lyu et al. gathered data from 31 US hospitals and found that patient satisfaction was associated with culture domains of the employee work climate, safety climate, and stress recognition but not with other variables such as performance on process measures, the hospital's overall safety culture score, or individual culture domains. ${ }^{15}$ Physician-related factors have also proven to be important in influencing patient satisfaction. Anderson and colleagues demonstrated that patient satisfaction is highly influenced by physician communication and follow-up care. ${ }^{2}$ Finally, the influence of intrinsic patient characteristics on satisfaction scores has also been examined. For example, preoperative expectations of surgical patients have been shown in multiple studies to influence postsurgical satisfaction. ${ }^{8,30,31,34}$ Our results suggest
TABLE 1. Patient demographics and characteristics of the study population

\begin{tabular}{|c|c|}
\hline Characteristic & Value (\%) \\
\hline No. of patients & 257 \\
\hline Age, yrs & $60 \pm 12.2$ \\
\hline Sex (female) & $151(59)$ \\
\hline Smoker & $14(5.5)$ \\
\hline \multicolumn{2}{|l|}{ Race } \\
\hline American Indian/Native American & $1(0.39)$ \\
\hline Asian & $6(2.3)$ \\
\hline Black/African American & $38(15)$ \\
\hline Native Hawaiian/Pacific Islander & 0 \\
\hline White & $210(82)$ \\
\hline Did not answer & $2(0.78)$ \\
\hline Hispanic & $4(1.6)$ \\
\hline \multicolumn{2}{|l|}{ Preoperative activation state } \\
\hline 1 (lowest stage) & $21(8.2)$ \\
\hline 2 & $30(12)$ \\
\hline 3 & $63(25)$ \\
\hline 4 (highest stage) & $143(56)$ \\
\hline \multicolumn{2}{|l|}{ Preoperative PROMIS domains } \\
\hline Pain & $64 \pm 7.5$ \\
\hline Physical function & $35 \pm 7.4$ \\
\hline Fatigue & $58 \pm 9.3$ \\
\hline Anxiety & $55 \pm 9.0$ \\
\hline Depression & $51 \pm 9.5$ \\
\hline Sleep & $56 \pm 9.4$ \\
\hline Social status & $40 \pm 8.7$ \\
\hline
\end{tabular}

Data are presented as the mean \pm SD or the number (\%) of patients.

that preoperative patient activation is an additional factor that may be used to predict postoperative satisfaction in spinal surgery patients, and they broaden our understanding of satisfaction in orthopedic surgery patients by revealing the degree to which this intrinsic patient factor is important in long-term satisfaction.

There are several potential explanations for our findings. Given that higher levels of patient activation are associated with adherence to physical therapy, ${ }^{23,24}$ the increased satisfaction reported by more activated patients may be due to improved postoperative recovery garnered by actively participating in postoperative care and recovery regimens. In addition, more highly activated patients may be seeking out their own regimens for improving postoperative recovery, which may, in turn, lead to improved satisfaction. Another potential explanation is that more activated patients are inherently more likely to be satisfied to an extent that supersedes actual postoperative improvement.

We also demonstrated a significant, but weak, correlation between patient activation and PROMIS health domains prior to surgery, indicating that patient activation is a separate construct from a patient's symptom burden. This may indicate that there are intrinsic patient charac- 

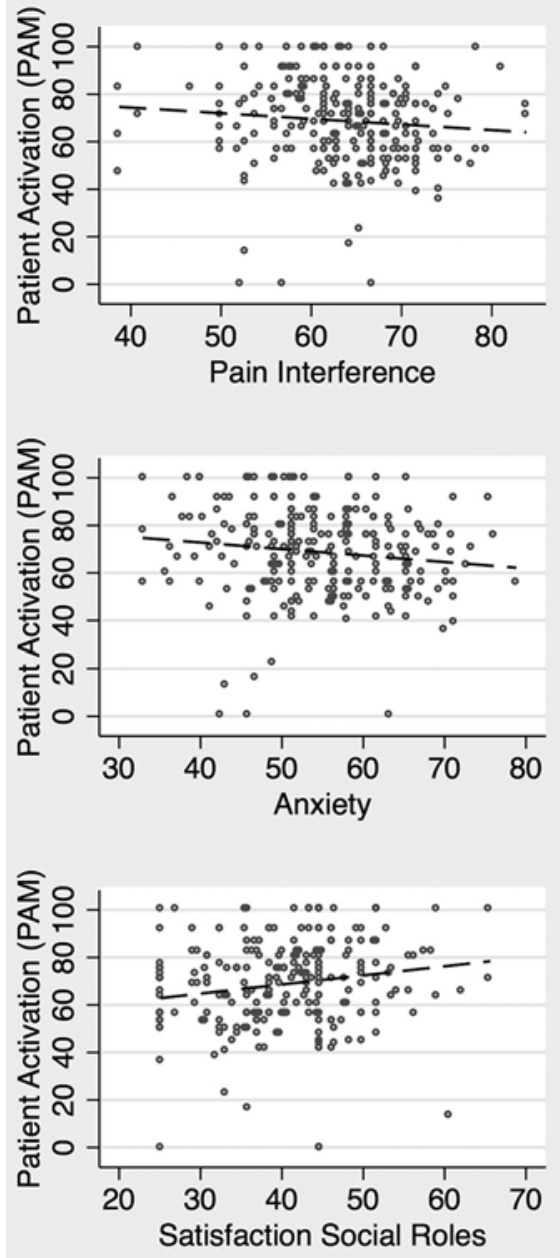
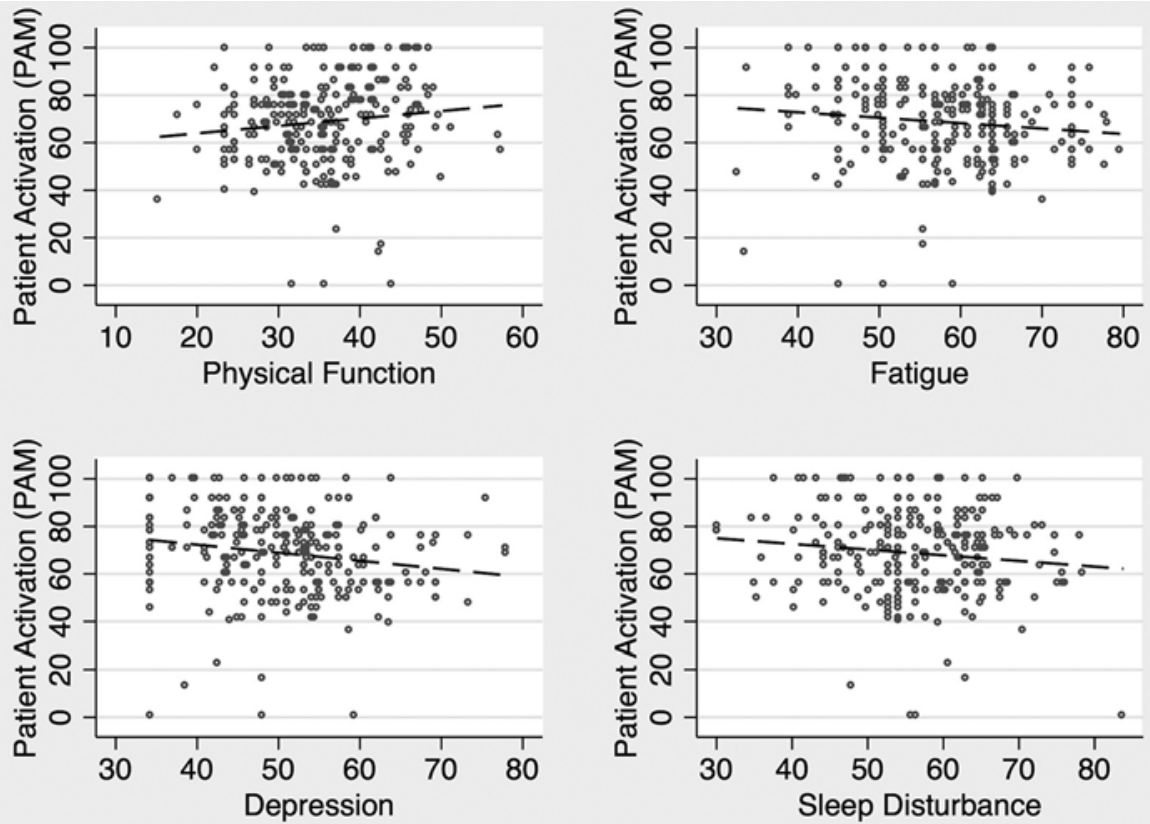

\begin{tabular}{|l|r|r|}
\hline PROMIS Domain & r & P value \\
\hline Pain Interference & -0.10 & 0.0721 \\
\hline Physical Function & 0.07 & 0.1823 \\
\hline Fatigue & -0.14 & $\mathbf{0 . 0 0 8 5}$ \\
\hline Anxiety & -0.15 & $\mathbf{0 . 0 0 4 3}$ \\
\hline Depression & -0.19 & $\mathbf{0 . 0 0 0 3}$ \\
\hline Sleep Disturbance & -0.07 & 0.1911 \\
\hline Satisfaction with Social Status & 0.20 & $\mathbf{0 . 0 0 0 2}$ \\
\hline
\end{tabular}

FIG. 2. Correlation between preoperative PROMIS domains and patient activation. The associations between the PAM scores (y axis) and PROMIS domains (x axis) are shown as a series of scatterplots. Each data point is represented by an open circle, while a best fine line is shown by a dashed line. The correlation coefficients and $p$ values are shown in the figure's table. The PROMIS domains of fatigue, anxiety, depression, and satisfaction with social status were significantly correlated with PAM scores (all $p<$ 0.05 ), though the strength of the correlation was weak (all $r \leq 0.2$ ). The PROMIS domains of pain interference, physical function, and sleep disturbance were not significantly correlated with PAM scores (all $p>0.05)$.

teristics, such as patient activation, that are separate from symptoms related to the spinal disorder requiring treatment that may contribute to varied levels of satisfaction following surgery. In addition, we found that although satisfaction was positively correlated with several PROMIS health domains, this correlation was relatively weak and certain domains, such as pain, physical function, and sleep disturbance, were not correlated with satisfaction. Furthermore, the PROMIS domain of satisfaction with social roles was negatively correlated with satisfaction. Although we have clearly outlined why patient satisfaction is important in individuals undergoing spine surgery, and this metric is being increasingly used to evaluate surgeon performance, our results show that patient-reported outcomes and satisfaction may not always be strongly linked to each other.

The clinical significance of this study relies on the idea that patient activation is a modifiable factor, and several studies have described interventions that have success- fully increased patient activation.,11,13,25,27,28 Houlihan et al. demonstrated in 2017 that a telephone-based empowerment intervention was able to improve PAM scores in patients with chronic spinal cord injury, in addition to improving secondary quality of life measures. ${ }^{13} \mathrm{We}$ previously conducted a prospective, randomized study using a telephone-based intervention in patients who have had spinal stenosis surgery and found that patient activation and engagement in postoperative rehabilitation are improved by this intervention, with concomitant improvement in functional outcomes and pain. ${ }^{26,27}$

There are several limitations to this study. First, while our data were collected prospectively, this research question was proposed retrospectively. Therefore, the potential for information and selection bias exists, which we have attempted to control for by adjusting for multiple demographic covariates and demonstrating that the relationship between patient activation and satisfaction still exists (and is even stronger) in individuals with incomplete follow-up. 
TABLE 2. Odds of satisfaction at various postoperative time points stratified by stages of preoperative patient activation

\begin{tabular}{cccr}
\hline Time Point & Activation State & OR $(95 \% \mathrm{Cl})$ & p Value \\
\hline 6 wks & 1 & & \\
\hline & 2 & $1.42(0.51-3.96)$ & 0.27 \\
\hline 3 mos & 3 & $4.75(1.87-12.0)$ & $<0.01$ \\
\hline & 4 & $3.06(1.25-7.51)$ & 0.01 \\
\hline 6 mos & 1 & & \\
\hline & 2 & $1.92(0.64-5.71)$ & 0.06 \\
\hline & 3 & $3.58(1.35-9.54)$ & 0.01 \\
\hline & 2 & $4.23(1.68-10.93)$ & $<0.01$ \\
\hline 12 mos & 3 & $3.27(0.96-11.13)$ & 0.06 \\
\hline & 4 & $5.36(1.74-16.50)$ & $<0.01$ \\
\hline & 1 & $5.41(1.98-14.78)$ & $<0.01$ \\
\hline & 2 & $1.82(0.89-3.75)$ & 0.10 \\
\hline & 3 & $2.82(1.49-5.33)$ & $<0.01$ \\
\hline
\end{tabular}

All analyses were adjusted for the following covariates: age, sex, race, highest level of education, and marital status. Boldface type indicates statistical significance.

Second, our cohort of patients is diagnostically heterogeneous, which was done purposefully in order to examine satisfaction across a large multiprovider spine surgery practice; however, there may be subgroups of patients who respond differently, depending on the level of preoperative patient activation. We also recognize that patients may be reluctant to express decisional regret following surgery and that we were unable to provide tangible reasons for the dissatisfaction seen in a minority of patients. Last, the PAM is a relatively novel questionnaire and has been validated to study patients undergoing lumbar spine surgery, but validation studies in patients undergoing cervical spine surgery have yet to be published. Despite these limitations, however, we have demonstrated a strong and consistent association between patient activation and satisfaction at several postoperative time points in a large sample of patients.

TABLE 3. Correlation between PROMIS domains and satisfaction at 1 year postoperatively

\begin{tabular}{lrr}
\hline \multicolumn{1}{c}{ PROMIS Domain } & \multicolumn{1}{c}{$r$} & p Value \\
\hline Pain & 0.08 & 0.19 \\
\hline Physical function & -0.08 & 0.20 \\
\hline Fatigue & 0.18 & $<0.01$ \\
\hline Anxiety & 0.21 & $<0.01$ \\
\hline Depression & 0.24 & $<0.01$ \\
\hline Sleep disturbance & 0.11 & 0.09 \\
\hline Satisfaction with social roles & -0.21 & $<0.01$ \\
\hline
\end{tabular}

Boldface type indicates statistical significance.

\section{Conclusions}

Patients undergoing elective spinal surgery at our institution present with varying levels of patient activation as measured by the PAM score, and those in the higher domains of activation had up to quadruple greater odds of having increased satisfaction after surgery. Patient activation has a weak relationship to a patient's symptom burden related to spinal pathology.

\section{References}

1. Al-Abri R, Al-Balushi A: Patient satisfaction survey as a tool towards quality improvement. Oman Med J 29:3-7, 2014

2. Anderson R, Barbara A, Feldman S: What patients want: a content analysis of key qualities that influence patient satisfaction. J Med Pract Manage 22:255-261, 2007

3. Camacho F, Anderson R, Safrit A, Jones AS, Hoffmann P: The relationship between patient's perceived waiting time and office-based practice satisfaction. N C Med J 67:409413, 2006

4. Cella D, Gershon R, Lai JS, Choi S: The future of outcomes measurement: item banking, tailored short-forms, and computerized adaptive assessment. Qual Life Res 16 (Suppl 1):133-141, 2007

5. Cella D, Riley W, Stone A, Rothrock N, Reeve B, Yount S, et al: The Patient-Reported Outcomes Measurement Information System (PROMIS) developed and tested its first wave of adult self-reported health outcome item banks: 2005-2008. J Clin Epidemiol 63:1179-1194, 2010

6. Daltroy LH, Cats-Baril WL, Katz JN, Fossel AH, Liang MH: The North American Spine Society Lumbar Spine Outcome Assessment Instrument: reliability and validity tests. Spine (Phila Pa 1976) 21:741-749, 1996

7. Druss BG, Zhao L, von Esenwein SA, Bona JR, Fricks L, Jenkins-Tucker S, et al: The Health and Recovery Peer (HARP) Program: a peer-led intervention to improve medical self-management for persons with serious mental illness. Schizophr Res 118:264-270, 2010

8. Ellis DJ, Mallozzi SS, Mathews JE, Moss IL, Ouellet JA, Jarzem P, et al: The relationship between preoperative expectations and the short-term postoperative satisfaction and functional outcome in lumbar spine surgery: a systematic review. Global Spine J 5:436-452, 2015

9. Gan TJ, Habib AS, Miller TE, White W, Apfelbaum JL: Incidence, patient satisfaction, and perceptions of post-surgical pain: results from a US national survey. Curr Med Res Opin 30:149-160, 2014

10. Harvey L, Fowles JB, Xi M, Terry P: When activation changes, what else changes? the relationship between change in patient activation measure (PAM) and employees' health status and health behaviors. Patient Educ Couns 88:338-343, 2012

11. Hibbard JH, Greene J: What the evidence shows about patient activation: better health outcomes and care experiences; fewer data on costs. Health Aff (Millwood) 32:207-214, 2013

12. Hibbard JH, Stockard J, Mahoney ER, Tusler M: Development of the Patient Activation Measure (PAM): conceptualizing and measuring activation in patients and consumers. Health Serv Res 39:1005-1026, 2004

13. Houlihan BV, Brody M, Everhart-Skeels S, Pernigotti D, Burnett S, Zazula J, et al: Randomized trial of a peer-led, telephone-based empowerment intervention for persons with chronic spinal cord injury improves health self-management. Arch Phys Med Rehabil 98:1067-1076.e1, 2017

14. Jensen JD, Allen L, Blasko R, Nagy P: Using quality improvement methods to improve patient experience. J Am Coll Radiol 13 (12 Pt B):1550-1554, 2016

15. Lyu H, Wick EC, Housman M, Freischlag JA, Makary MA: 
Patient satisfaction as a possible indicator of quality surgical care. JAMA Surg 148:362-367, 2013

16. Philp S, Carter J, Pather S, Barnett C, D'Abrew N, White K: Patients' satisfaction with fast-track surgery in gynaecological oncology. Eur J Cancer Care (Engl) 24:567-573, 2015

17. Pilkonis PA, Choi SW, Reise SP, Stover AM, Riley WT, Cella D: Item banks for measuring emotional distress from the Patient-Reported Outcomes Measurement Information System (PROMIS $®)$ : depression, anxiety, and anger. Assessment 18:263-283, 2011

18. Purvis TE, Andreou E, Neuman BJ, Riley LH III, Skolasky RL: Concurrent validity and responsiveness of PROMIS health domains among patients presenting for anterior cervical spine surgery. Spine (Phila Pa 1976) 42:E1357-E1365, 2017

19. Purvis TE, Neuman BJ, Riley LH III, Skolasky RL: Discriminant ability, concurrent validity, and responsiveness of PROMIS health domains among patients with lumbar degenerative disease undergoing decompression with or without arthrodesis. Spine (Phila Pa 1976) 43:1512-1520, 2018

20. Remmers C, Hibbard J, Mosen DM, Wagenfield M, Hoye RE, Jones C: Is patient activation associated with future health outcomes and healthcare utilization among patients with diabetes? J Ambul Care Manage 32:320-327, 2009

21. Schmocker RK, Cherney Stafford LM, Siy AB, Leverson GE, Winslow ER: Understanding the determinants of patient satisfaction with surgical care using the Consumer Assessment of Healthcare Providers and Systems surgical care survey (S-CAHPS). Surgery 158:1724-1733, 2015

22. Skolasky RL, Mackenzie EJ, Riley LH III, Wegener ST: Psychometric properties of the Patient Activation Measure among individuals presenting for elective lumbar spine surgery. Qual Life Res 18:1357-1366, 2009

23. Skolasky RL, Mackenzie EJ, Wegener ST, Riley LH III: Patient activation and adherence to physical therapy in persons undergoing spine surgery. Spine (Phila Pa 1976) 33:E784E791, 2008

24. Skolasky RL, Mackenzie EJ, Wegener ST, Riley LH III: Patient activation and functional recovery in persons undergoing spine surgery. J Bone Joint Surg Am 93:1665-1671, 2011

25. Skolasky RL, Maggard AM, Li D, Riley LH III, Wegener ST: Health behavior change counseling in surgery for degenerative lumbar spinal stenosis. Part I: improvement in rehabilitation engagement and functional outcomes. Arch Phys Med Rehabil 96:1200-1207, 2015

26. Skolasky RL, Maggard AM, Li D, Riley LH III, Wegener ST: Health behavior change counseling in surgery for degenerative lumbar spinal stenosis. Part II: patient activation mediates the effects of health behavior change counseling on rehabilitation engagement. Arch Phys Med Rehabil 96:1208-1214, 2015

27. Skolasky RL, Maggard AM, Wegener ST, Riley LH III: Telephone-based intervention to improve rehabilitation engagement after spinal stenosis surgery: a prospective lagged controlled trial. J Bone Joint Surg Am 100:21-30, 2018
28. Terry PE, Fowles JB, Xi M, Harvey L: The ACTIVATE study: results from a group-randomized controlled trial comparing a traditional worksite health promotion program with an activated consumer program. Am J Health Promot 26:e64-e73, 2011

29. Tevis SE, Kennedy GD, Kent KC: Is there a relationship between patient satisfaction and favorable surgical outcomes? Adv Surg 49:221-233, 2015

30. Thompson AG, Suñol R: Expectations as determinants of patient satisfaction: concepts, theory and evidence. Int J Qual Health Care 7:127-141, 1995

31. Toyone T, Tanaka T, Kato D, Kaneyama R, Otsuka M: Patients' expectations and satisfaction in lumbar spine surgery. Spine (Phila Pa 1976) 30:2689-2694, 2005

32. Tsai TC, Orav EJ, Jha AK: Patient satisfaction and quality of surgical care in US hospitals. Ann Surg 261:2-8, 2015

33. Tzeng A, Tzeng TH, Vasdev S, Grindy A, Saleh JK, Saleh KJ: The role of patient activation in achieving better outcomes and cost-effectiveness in patient care. JBJS Rev 3:3, 2015

34. Waljee J, McGlinn EP, Sears ED, Chung KC: Patient expectations and patient-reported outcomes in surgery: a systematic review. Surgery 155:799-808, 2014

\section{Disclosures}

Dr. Riley reports being on the board of directors for LifeNet Health.

\section{Author Contributions}

Conception and design: Skolasky, Harris. Acquisition of data: Skolasky, Harris. Analysis and interpretation of data: Skolasky, Harris. Drafting the article: all authors. Critically revising the article: all authors. Reviewed submitted version of manuscript: all authors. Approved the final version of the manuscript on behalf of all authors: Skolasky. Statistical analysis: Skolasky, Harris. Administrative/technical/material support: Skolasky. Study supervision: Skolasky.

\section{Supplemental Information \\ Previous Presentations}

North American Spine Society Annual Meeting, September 27, 2018, Los Angeles, California.

\section{Correspondence}

Richard L. Skolasky: The Johns Hopkins University, Baltimore, MD.rskolas1@jhmi.edu. 